\title{
As correntes do pensamento geográfico e a Geografia ensinada no Ensino Fundamental: objetivos, objeto de estudo e a formação dos conceitos geográficos
}

\author{
Lia Fialho ${ }^{1}$ \\ Charliton Machado ${ }^{2}$ \\ José Álbio Moreira de Sales ${ }^{3}$
}

\section{Resumo}

Este artigo discute acerca das interfaces das correntes do pensamento geográfico e a Geografia ensinada no Ensino Fundamental, com ênfase na "alfabetização geográfica" no século XXI. Para privilegiar o referido escopo, foi realizado um estudo de cunho teórico que culminou na dissertação sobre as influências que a corrente Tradicional - determinismo, possibilismo, regionalismo - e a Moderna - pragmática, crítica - exerceram no ensino formal da Geografia, bem como na maneira como a aprendizagem foi concebida historicamente, lançando luz aos objetivos, objeto de estudo e a constituição dos conceitos geográficos pela criança. Constatou-se que, na contemporaneidade, não cabe mais uma visão positivista de ensino baseada unicamente na transmissão

\footnotetext{
1 Doutora em Educação Brasileira pela UFC. Professora da Universidade Estadual do Ceará - UECE, Brasil. lia_fialho@yahoo.com.br

2 Doutor em Educação pela UFRN. Professor dos Programas de Pós-Graduação em Educação e em Sociologia da UFPB, Brasil. charlitonlara@yahoo.com.br

3 Doutor em História pela UFPE. Professor da UECE, Brasil. albiosales@gmail.com
} 
mnemônica. Ao contrário, deve-se compreendê-lo como instrumento de compreensão da realidade. Sugere-se desenvolver o conhecimento geográfico desde a tenra infância, propiciando aprendizagem contextualizada, correlacionando sujeito, tempo e espaço em uma perspectiva hermenêutica de produção e transformação da sociedade.

Palavras-Chave: correntes geográficas; geografia ensinada; aprendizagem; educação.

\title{
The lines of the geographical thought taught in elementary education: objectives, object of study and construction of geographical concepts.
}

\begin{abstract}
This article has the objective of discussing the interfaces between the lines of geographical thought and geography taught in elementary school with emphasis on "geographic literacy" in the XXI century. To contemplate the scope above a theoretical study was done culminating in a dissertation on the influence that the Traditional line- determinism, possibilism, regionalism - and the Modern line- pragmatic, critical - exerted on the formal teaching of geography as well as in the way this learning process was historically designed, shedding light to the objectives, subject of study and the construction of geographical concepts by the child. It was noted that, in contemporary times, it is no longer a positivist view of education based solely on mnemonic transmission instead should understand it as a tool for understanding reality. It is suggested to develop geographic knowledge from the early childhood, providing contextualized learning, co-relating the subject, time and space in a hermeneutic perspective of production and transformation of society.

Keywords: geographical lines; geography taught; learning; education.
\end{abstract}




\section{Introdução}

A Geografia ensinada foi influenciada pelas correntes do pensamento geográfico de tal maneira que, ainda no século XXI, características oriundas do tradicionalismo se perpetuam na práxis pedagógica do docente, interferindo diretamente na aprendizagem do aluno. Como componente curricular, o estudo da Geografia possibilita, mediante a alfabetização geográfica responsável, o desenvolvimento de habilidades que facilitam a compreensão do espaço geográfico de maneira consciente. Para isso, no entanto, fazem-se necessários alguns cuidados na mediação do conhecimento nas primeiras séries da escolarização.

Este artigo objetiva debater a respeito das interfaces das correntes do pensamento geográfico e a Geografia transferida no Ensino Fundamental, com ênfase na "alfabetização geográfica" no século XXI, visando a refletir sobre os objetivos, objeto de estudo e a formação dos conceitos geográficos pela criança. Para cobrir esse objetivo, foi desenvolvido um estudo de cunho teórico que culminou na dissertação sobre as características das correntes geográficas Tradicional e Moderna e suas influências no ensino formal da Geografia. Debateu-se, ainda, a respeito da maneira de mediação e apreensão de conhecimentos no âmbito geográfico, ressaltando a concepção de aluno e professor no ensino e na aprendizagem na contemporaneidade.

Iniciando pela descrição da ideia de Geografia adotada no determinismo, possibilismo, regionalismo, Geografia pragmática e Geografia crítica, de maneira sucinta, são expressos pontos de congruências e divergências que interferiram no fazer pedagógico do professor no Ensino Fundamental, historicamente. Em seguida, discutem-se as ideias mais consensuais sobre o fomento do ensino geográfico, que, em suma, se direcionam para uma perspectiva crítica, que busca trabalhar saberes de maneira contextualizada, relacionando-os nas suas multidimensionalidades, tornando-os significativos.

Ressalta-se que a didática com foco no professor como detentor e transmissor de conteúdos estáticos, que desenvolve o processo educativo com operações mnemônicas voltadas para enumeração mecânica de 
rios, vegetação, países, cidades, regiões, entre outras informações descontextualizadas, com caráter enciclopédico, não é mais admitida.

Ao contrário de uma óptica positivista, baseada unicamente na transmissão mnemônica, o ensino deve ser compreendido como instrumento de compreensão da realidade. A Geografia ensinada no século XXI objetiva desenvolver, desde a tenra infância, a vivência e análise de experiências pluridisciplinares, impulsionando o desenvolvimento do entendimento das complexidades dos fenômenos humanos no espaço. Correlacionando sujeito, tempo e espaço em uma perspectiva hermenêutica, o aluno, estimulado pela mediação do professor, desenvolve saberes e habilidades que fomentam a capacidade de produção e transformação da sociedade, por intermédio da atuação cidadã autônoma, amparada por uma visão crítica da realidade.

O artigo enseja, pois, uma reflexão acerca da Geografia ensinada nas primeiras séries de escolarização da educação formal, na medida em que discute os objetivos, o objeto de estudo e a formulação dos conceitos geográficos, estabelecendo uma conexão com a atuação do pedagogo e a formação do aluno. Problematizando a didática do professor e a aprendizagem discente no contexto educacional, sinaliza na direção de um ensino de Geografia que considera as representações de vida dos alunos e articula o formalismo teórico da Ciência aos conhecimentos cotidianos, tornando-os significativos e aplicáveis na prática social.

\section{Interfaces das correntes geográficas com o ensino da Geografia}

Ainda que o construto Geografia remonte à Antiguidade Clássica, na perspectiva da Geodésia, não havia uma unidade, de modo que, até o final do século XVIII, não é possível falar de conhecimento geográfico, como algo padronizado, com unidade mínima para ser considerada ciência (CAVALCANTI; VIADANA, 2010). O termo Geografia era utilizado para designar escritos literários, relatos de viagens, descrição de lugares, relatórios estatísticos simplórios, entre outros aportes (GODOY, 2010).

Apenas no início do século XIX, começou a ocorrer a sistematização do saber geográfico de modo autônomo e particular, desde a aquisição de 
alguns princípios: do conhecimento da extensão do planeta, permitindo que a Terra fosse pensada de maneira unitária; do levantamento de dados de pontos diversos da superfície terrestre; do aprimoramento das técnicas cartográficas, o que possibilitou a representação dos fenômenos observados e da localização dos territórios; e do aparecimento das teorias do evolucionismo, que forneceu uma base científica para as indagações geográficas (MORAES, 1994).

As primeiras manifestações, no sentido de uma Geografia sistematizada, aparecem nos escritos de Alexander von Humboldt e Carl Ritter. O primeiro entende Geografia como uma síntese dos conhecimentos relativos à Terra e propõe a intuição com suporte na observação - o empirismo racionado; o outro compreende que a Geografia deveria estudar os "sistemas naturais" individuais e compará-los, na perspectiva do estudo dos lugares (LACOSTE, 1988). Tais teóricos foram os precursores das primeiras correntes do pensamento geográfico sistematizado.

Na inteligência de Moraes (1994), as correntes do pensamento geográfico, com suas congruências e divergências, podem ser classificadas em dois grandes grupos: a Tradicional, sustentando em conceitos naturais e percebendo a Geografia como Ciência descritiva de observação de elementos naturais; e a Moderna, que critica o positivismo e acolhe a Geografia como Ciência social.

Os conjuntos das correntes não dialéticas que estudam a relação do homem com a natureza, sem se preocupar com as interfaces dos homens e as questões sociais, compõem a Geografia Tradicional. De modo simplório, elas podem ser assim compreendidas: Determinismo, com F. Ratzel como principal teórico, defendendo o argumento de que as condições naturais determinam o comportamento do homem, interferindo na sua capacidade de progredir; Possibilismo, fundamentado, principalmente, por P. V. de La Blache, que adotava a ideia de que a natureza fornecia possibilidades para que o homem a modificasse sem necessariamente determinar comportamentos; e Regionalismo, com bases também em P. V. de La Blache e Richard Hartshorne, que focaliza o estudo das áreas e sua diferenciação mediante a descrição dos lugares e divisões territoriais (ALVES; SAHR, 2009). Essas foram questionadas com o movimento da renovação, a expansão 
capitalista e o fim da Segunda Guerra Mundial por volta de 1950.

As tendências que defendiam fazer da Geografia uma Ciência social e criticavam o tradicionalismo foram denominadas de Modernas (MORAES, 1994). A Geografia Moderna pode ser subdividida em duas vertentes: a Pragmática e a Crítica. A primeira diz respeito à Geografia aplicada (teorética ou quantitativa, sistêmica e comportamental ou de percepção). Ela acreditava em uma tecnologia geográfica que, mediante dados estatísticos e diagnósticos estruturados, subsidia tomada de decisões de empresas e do governo, e é criticada por legitimar a expansão das relações capitalistas (SAHR, 2006). A segunda - a Crítica - possui inúmeros teóricos e propostas díspares, mas converge na oposição a uma realidade social contraditória, desigual e injusta, e entende a Geografia como ciência politizada que visa à transformação da ordem social em busca de uma sociedade mais justa (GODOY, 2010). Nesta, a Geografia é uma prática social em relação à superfície terrestre (LACOSTE, 1988) que responde a problemas por meio da prática social (HARVEY, 1993) para que não se torne uma prisão (SANTOS, 1994). Importa salientar que o pendor Humanista, ao contrário do Físico, é assentado na subjetividade, nos sentimentos, na experiência, privilegiando o singular e a compreensão como base da inteligibilidade do mundo real (CORRÊA, 1998).

A Geografia, na condição de Ciência social, possui em seu arcabouço um conjunto de categorias que expressam sua identidade. Ao pensálas, considerando a ação do homem e a superfície terrestre, bem como as suas inter-relações, surgem visões e interpretações particulares (ROCHA, 2008). Vale esclarecer que as correntes do pensamento geográfico representam conceitos antagônicos, que podem convergir ou se complementar em alguns aspectos, e elas emergiram em determinado espaço e tempo numa elaboração sócio-histórica (CORRÊA, 1998). Dessa maneira, foram influenciadas pelo contexto histórico ao mesmo tempo em que influenciaram a maneira de se ensinar Geografia (SAHR, 2006).

Na propensão Tradicional, a Geografia ensinada era pautada por uma prática educativa baseada no modelo positivista em que a tendência pedagógica liberal (tradicional, renovada e tecnicista) se sobressaía e se caracterizava pela didática com foco no professor 
como detentor e transmissor de conteúdos, estigmatizando o processo educativo em operações mnemônicas voltadas para enumeração mecânica de rios, vegetação, países, cidades, regiões, entre outras informações descontextualizadas, com caráter enciclopédico, sem desenvolver análise crítica sobre os conhecimentos, perpetuando a ordem e ideologia vigente (OLIVEIRA, 1998). Straforini (2004) comunga com o exposto, quando exprime:

O objetivo da escola tradicional é a transmissão de conhecimento, ou seja, uma preocupação conteudista. Dessa forma, o aluno é visto como um agente passivo, cabendo a ele decorar e memorizar o conjunto de conhecimentos significativos da cultura da humanidade previamente selecionados e transmitidos pelo professor em aulas expositivas. O mundo é uma externalidade ao aluno, ou seja, não é dado a ele a possibilidade de sua inserção no processo histórico [...] (p. 57)

Diferentemente da inclinação Tradicional, na Moderna não se concebe mais uma educação pautada em conhecimentos fragmentados, estanques e decorados por intermédio do autoritarismo. Ao contrário, ela é pautada na autonomia, mediação pedagógica, utilização de múltiplas linguagens e internalização significativa de experiências de aprendizagem, sendo o aluno conduzido a analisar a realidade social que o cerca na condição de agente transformador das dinâmicas históricas que perpassam a espacialidade. Vesentini (1993), retratando acerca do novo paradigma do ensino da Geografia na perspectiva Moderna, acrescenta:

O ensino da geografia no século XXI, portanto, deve ensinar, ou melhor, deve deixar o aluno descobrir - o mundo em que vivemos, com especial atenção para as escalas local e nacional, deve enfocar criticamente a questão ambiental e as relações sociedade/natureza (sem embaralhar uma dinâmica na outra), deve realizar constante mente estudos do meio (para que o conteúdo ensinado não seja meramente teórico ou "livresco" e sim real, ligado à vida cotidiana das pessoas) e deve levar os educadores a interpretar textos, fotos, mapas, paisagens. E por esse caminho, e somente por ele, que a geografia escolar vai sobrevivendo e até mesmo ganhando novos espaços nos melhores sistemas educacionais. (p. 219)

O ensino da Geografia moderna, todavia, deve ser ministrado numa perspectiva progressista (libertadora, crítico-social dos conteúdos) 
que concebe o aluno como foco do ensino-aprendizagem, detentor de autonomia e apto ao desenvolvimento cognitivo e intelectual (PENTEADO, 2010). Sob tal aspecto, ao professor cabe instigar com problematizações e mediar o conhecimento para facilitar a assimilação e internalização de saberes (VYGOTSKY, 1999).

A Geografia repassada tradicionalmente foi quase invisibilizada, sendo concebida fisicamente numa concepção despolitizada - ou servindo primeiramente para "fazer guerra" (LACOSTE, 1988), ou seja, politizada para fins políticos, militares e econômicos sob a óptica da luta de classes (VESENTINI, 1988).

Os saberes geográficos, atualmente, foram considerados como estratégicos, não apenas como instrumento de poder como centra foco a Geografia marxista, mas, principalmente, como meio para se compreender a inter-relação homem-lugar numa perspectiva também humana, não só física. Em contato direto com as Ciências sociais, o conhecimento geográfico deve considerar fatores econômicos, sociais, culturais e políticos em uma nova Geografia crítica que se apropria dos aspectos qualitativos (SANTOS, 1994).

Ao considerar que a Geografia abrange fenômenos econômicos, sociais, políticos, culturais e militares, englobando também os aspectos "físicos" e ecológicos, necessita-se entender que as transformações planetárias perpassam a Geografia e a leitura do mundo por intermédio de um raciocínio geográfico complexo, que permite a compreensão de como esses fatores se combinam diferentemente. Por isso, na Geografia ensinada, busca-se desenvolver, desde a infância, a vivência e análise de experiências pluridisciplinares (CASTELLAR, 2000) e específicas que propiciem compreender a complexidade dos fenômenos humanos sobre o terreno em envergadura planetária (MORIN; ROGER; MOTTA, 2007).

\section{A Geografia no Ensino Fundamental: objetivos, objeto de estudo e a elaboração dos conceitos geográficos}

Antes de prelecionar sobre o ensino da Geografia, é oportuno notar que o ensino pode ocorrer de várias maneiras: formal, com a educação escolar sistemática, intencional e com objetivos previamente definidos; não 
formal, também intencionalmente, mas sem sistematização; e informal, sem intenção, de modo espontâneo e não sistemático (LIBÂNEO, 1994). Esta última acontece no seio familiar e da sociedade que circunda a criança ainda pequenina, de tal maneira que, desde o nascimento, o bebê, paulatinamente, adentra o mundo adulto por intermédio de suas experimentações e internalizações individuais mediadas por seus pares e pela sociedade na qual se insere (PIAGET; INHELDER, 1993).

A Geografia ensinada na escola se refere à educação formal. Em uma concepção crítica, parte-se da compreensão de que cada sujeito é único e faz suas percepções e elaboração em suporte em suas individualizações, não havendo uma receita pronta para se trabalhar o conhecimento específico da Geografia, que se inicia de maneira informal desde os primeiros anos de vida. Ensinar Geografia, contudo, suscita do professor a capacidade investigativa para conhecer os saberes prévios dos alunos de maneira particularizada, e, desde a identificação do que já restou elaborado, promover a problematização contextualizada, instigando a curiosidade e os respectivos anseios dos estudantes pela busca do conhecimento.

Importa salientar que a Teoria de Desenvolvimento Cognitivo (Piaget), muito difundida no Brasil - que dividia a aprendizagem infantil em estádio delimitados etariamente (até dois anos, sensóriomotor, de dois a sete, pré-operatório, de sete a 12, operacional concreto, e desde os 12, operacional formal ou abstrato) -, influenciou o ensino geográfico e levou muitos educadores a acreditar que a criança do Ensino Fundamental não conseguiria apreender inúmeros conceitos geográficos, porque estes eram abstratos e não havia maturação biológica para sua internalização no ensino infantil e primeiras séries do Ensino Fundamental (FREITAS, 2010), deixando de estimular o desenvolvimento dos conceitos e das categorias de análise geográficas. Com a difusão da teoria de Vygotsky - que entende a formação da consciência e suas funções psicológicas superiores com origem na ação do sujeito em relação com aparatos socioculturais e não apenas por um progresso intrínseco e linear -, foi possível ampliar a compreensão de que a mediação é essencial desde os primeiros anos, para que haja evolução constante da zona de desenvolvimento proximal, possibilitando passar da zona real 
para potencial com a formação de pseudoconceitos.

Cavalcanti (2005) tenta explicar a aprendizagem, considerando não apenas o desenvolvimento biológico, mas também a evolução das funções psicológicas superiores, com origem individual, quando acentua:

A internalização é um processo de reconstrução interna, intrassubjetiva, de uma operação externa com objetos que o homem entra em interação. Trata-se de uma operação fundamental para o processo de desenvolvimento de funções psicológicas superiores e consiste nas seguintes transformações: de uma atividade externa para uma atividade interna e de um processo interpessoal para um processo intrapessoal. (p. 188)

A pessoa realiza suas apreensões por intermédio das vivências sociais e culturais e desenvolve em cadência a criação da consciência desde essas experiências concebidas de maneira individualizada. Assim, o desenvolvimento das funções psicológicas superiores e da capacidade de abstração, necessária para compreensão de conceitos e categorias geográficas, resulta da interação sociocultural, devendo a mediação ser exercida desde cedo, com vistas a estimular o desenvolvimento.

Deleuze e Guattari (1992) relatam que o pintor não pinta sobre uma tela virgem, tampouco o escritor escreve em cima de uma página branca, porque a página ou a tela estão já cobertas de clichês preexistentes. Nessa vertente de pensamento, para mediar a aprendizagem no Ensino Fundamental, não se deve "apagar" ou ignorar os conhecimentos preexistentes elaborados pela leitura de mundo, mas se torna essencial levar em consideração a bagagem que o aluno já traz consigo (GADOTTI, 2004). Estimulando-se a criatividade e o interesse da criança por intermédio de uma mediação pedagógica responsável, é possível ensejar maior desenvolvimento da visão espacial da criança mediante a ampliação da capacidade de abstração.

O objetivo principal de estudo em Geografia, contudo, continua sendo, desde os primórdios, o espaço, mas na atualidade este é entendido como um produto histórico, "um conjunto de objetos e de ações que revela as práticas sociais dos diferentes grupos que vivem num determinado lugar, interagem, sonham, produzem, lutam e o (re) constroem." (CASTROGIOVANNI, 2006, p. 7). Nessa perspectiva, 
o ensino da Geografia deve levar em consideração as representações de vida dos alunos, articulando o formalismo teórico da Ciência aos conhecimentos cotidianos (FREIRE, 1996) e, ao contrário da Geografia puramente física, de cunho pedagógico maçante e inútil, ele se apresenta embebido da prática e permeado de reflexões epistemológicas que envolvem a pessoa humana e o lugar.

O espaço geográfico configura campo de produção e reprodução das relações sociais, que, malgrado submetido à lei da totalidade, possui certa autonomia (SANTOS, 1978); entrelaçado por questões de cunho econômico, político e social, não pode ser compreendido de maneira estática ou dissociada do dinamismo das ações humanas. Segundo Lefébvre (1976, p. 34), ele "estaria essencialmente vinculado com a reprodução das relações (sociais) de produção", mas não pode ser definido como produto ou objeto, na condição de receptáculo que apenas engloba coisas.

Ao contrário de Richard Hartshorne (1939), que defendia uma concepção idiográfica de espaço, este, na atualidade, é lócus da experiência social, permeado por subjetividades, crenças e culturas (ISNARD, 1982), que não se esgota em conceito único por possuir caráter multidimensional. Corrêa (2003) resume o exposto quando escreve:

Eis o espaço geográfico, a morada do Homem. Absoluto, relativo, concebido como planície isotrópica, representado através de matrizes e grafos, descrito através de diversas metáforas, reflexo e condição social, experienciados de diversos modos, rico em simbolismos e campos de lutas, o espaço geográfico é multidimensional. Aceitar esta multidimencionalidade é aceitar por práticas sociais distintas que, como HARVEY (1973) se refere, permitem construir diferentes conceitos de espaço. (p. 44)

Com amparo na compreensão hermenêutica de espaço geográfico, o objetivo do ensino da Geografia nas primeiras séries de escolarização é "alfabetizar espacialmente" o aluno, ou seja, mediar aprendizagens para que o estudante adquira noções de localização, organização, representação e entendimento da estrutura do espaço elaborado dinamicamente pelas sociedades (CASTELLAR, 2000), aprendendo a ler, lendo o espaço, ou seja, compreendendo o mundo com olhar espacial (CALLAI, 2005). Preocupando-se com o espaço e suas multidimensões, a Geografia no Ensino Fundamental parte da construção da própria 
identidade da criança, que se torna "o lastro para a descentração espaçotemporal do sujeito cidadão" (CASTROGIOVANNI, 2006, p. 13).

Trabalhar com os conceitos geográficos, nessa perspectiva, torna-se oportuno. É preciso, entretanto, compreender que eles são representações mentais, ideias que possuem a função genérica de identificar, descrever e classificar, propiciando conhecer os elementos que constituem a experiência humana. Nem toda palavra é um conceito, porque, para se constituir conceito, ela precisa trazer consigo uma série de significados que possibilitam interpretações de proposições compiladas em um construto (FREITAS, 2010).

A Geografia, efeita ciência social, ao estudar a ação do homem e a superfície terrestre, bem como as suas inter-relações, constitui, em seu arcabouço, um conjunto de conceitos específicos que expressam sua identidade (ROCHA, 2008). Ao se apropriar, cadencialmente, desse corpo conceitual, a criança desenvolve uma linguagem geográfica que possibilita "um olhar espacial" do mundo (CALLAI, 2005).

A "alfabetização geográfica" transita pela formulação dos conceitos, desencadeados no fenômeno de conhecer o mundo com arrimo na vida cotidiana e da compreensão do lugar concreto no qual se está inserido, e se consolida com a apropriação crítica e reflexiva, propiciando uma ação consciente e cidadã no mundo (MARQUES, 1993; CASTROGIOVANNI, 2006; CASTELLAR, 2000). O desenvolvimento dos conceitos Geográficos de maneira responsável facilita o alcance dos objetivos propostos para o ensino da geografia nas séries iniciais.

Segundo os Parâmetros Curriculares Nacionais (PCN), os objetivos gerais da Geografia para o Ensino Fundamental são oito, sintetizandoos se pode citar: 1) conhecer a organização do espaço geográfico e funcionamento da natureza em suas múltiplas relações, possibilitando compreender o papel das sociedades na construção e produção do território, paisagem e lugar; 2) identificar e avaliar as ações dos homens em sociedade e suas consequências nos diferentes espaços e tempos, possibilitando participação positiva no ambiente; 3) compreender a espacialidade e temporalidade nas suas interações; 4) compreender que as melhorias nas condições de vida são conquistas decorrentes de conflitos e negociações, mas que ainda não são usufruídas por todos e 
é necessário empenho na democratização; 5) conhecer e saber utilizar os procedimentos de pesquisa geográfica para compreender o lugar, território, paisagem e espaço; 6) saber utilizar a linguagem cartográfica; 7) valorizar o patrimônio sociocultural e respeitar a sociodiversidade; 8) fazer leitura de diferentes fontes de informação para interpretar, relacionar e analisar informações sobre o espaço geográfico (BRASIL, 1997).

Torna-se oportuno esclarecer que os PCN receberam inúmeras críticas acerca da elaboração do conteúdo do documento (NEVES, 2000): consulta e participação dos professores e pesquisadores brasileiros praticamente inexistiu, representa uma política neoliberal de privatização da educação nacional, atenta a interesses de organismos internacionais de financiamento, ignora as condições precárias de salário e recursos para o trabalho do professor, é pobre e pouco esclarecedora em termos teóricos, faz uso acrítico de correntes teóricas, despreza a historicidade de conceitos, entre outras (OLIVEIRA, 2003). O documento continua, no entanto, sendo utilizado como aparato norteador e os objetivos, conceitos e categorias geográficas ainda permanecem válidos como parâmetros para o ensino da Geografia no Ensino Fundamental.

Cabe comentar que, para alcançar os objetivos descritos nos PCN, é necessário mostrar ao aluno que cidadania também compreende o sentimento de pertença a uma realidade repleta de relações entre homem e natureza que devem ser analisadas, e, para tal, se torna oportuno desenvolver procedimentos de pesquisa que considere a observação, a descrição, o registro, a representação, a analogia, a explicação e síntese (PENTEADO, 2010).

Penteado (2010) defende uma proposta para que a Geografia ensinada seja concebida como instrumento de compreensão da realidade, em que esta se inicia pela problematização de fenômenos mais concretos aos abstratos e, por intermédio do respeito aos níveis de ensino - exploratório, desenvolvimento de conceitos específicos e ampliação de conceitos -, sugere um rol de atitudes que ultrapasse o ensino reprodutivo, decorativo, para o produtivo, com origem na experimentação e compreensão dos conceitos e categorias fundamentais. Tal postulado sinaliza uma visão sintética.

De acordo com Santos (1978), há duas abordagens mais convencionais 
no ensino da Geografia: a sintética e a analítica. Alves e Sahr (2009, p. 55) as explicam: "a sintética, que apresenta a realidade como ponto de partida, e a analítica, que parte do estudo da superfície terrestre no seu conjunto para posteriormente se chegar ao lugar de convivência". É mister compreender, todavia, que, apesar da abordagem sintética ter sido a mais difundida e utilizada no ensino da geografia nas últimas décadas, não se pode perder de vista a articulação entre o local e o global. Desse modo, a abordagem analítica também deve ser empregada no ensinoaprendizagem, porque permite uma visão cíclica de temporalidade, desfaz a hierarquização do saber geográfico e propicia a ampliação de outras maneiras de desenvolver abstrações.

Dados os objetivos mencionados nos PCN, não é difícil perceber as categorias de análise fundamentais nessa etapa da escolarização: lugar, território, paisagem e espaço (BRASIL, 1997; RIBEIRO; MARQUES, 2001). Diversos estudiosos pesquisam e conceituam essas categorias, e, nos últimos anos, há certa convergência em algumas definições que, de modo conciso, e um tanto superficial, podem ser descritas da seguinte maneira: a paisagem é a unidade visível que os sentidos conseguem perceber, compreendida como a relação entre homem e meio no estudo da cultura (CALLAI, 2005); o lugar seria concebido pela significação a percepção sensorial, possui um "espírito" e uma "personalidade" constituídos pela longa vivência (MASSEY, 2000); o território é o espaço definido e delimitado com supedâneo nas relações de poder e nas dimensões políticas, econômicas e culturais simbólicas (CLAVAL, 1999); o espaço geográfico representa a sociedade, o processo histórico por ela constituído na paisagem (CORRÊA, 2003; SANTOS, 1994). Vale mencionar, entretanto, a ideia de que tornar essas categorias inteligíveis não é tarefa simples, porque elas são abstratas e multidimensionais, exigindo do educador atitude crítica e dinâmica.

O domínio das categorias é relevante para desenvolver na criança a compreensão sociocultural e do funcionamento da natureza que a cerca, bem como propiciar a utilização, de maneira singular, do pensar sobre a realidade com olhar geográfico crítico, pois mediada pela análise do lugar e, consecutivamente, das demais categorias, a criança evolui da visão de espaço perceptivo, para representativo, desenvolvendo maturação para 
sair das relações meramente topológicas, limitadas ao objeto, e evoluir para as projetivas e euclidianas, que correlaciona os objetos entre si sem referência estática (CASTELLAR, 2005). Castrogiovanni (2006) explicita:

É preciso fazer a distinção entre o espaço da ação ou perceptivo e o espaço representativo: o primeiro se constrói em contato direto com o objeto, ou seja, através dos sentidos. Já o espaço representativo é construído na ausência do objeto, portanto é reflexivo. (p. 16)

Quando o aluno ultrapassa a percepção do espaço vivido e concebido concretamente e logra desenvolver a capacidade de perceber também o não experimentado, realizando abstrações, da maneira reflexiva, tornase possível a alfabetização espacial, que se efetiva com a tomada de consciência do espaço geográfico de maneira crítica.

Salienta-se, no entanto, não ser possível que o professor ensine definição de conceitos e categorias aos alunos. Ele, no máximo, os apresenta, porque o aluno, como sujeito ativo e autônomo, é quem vai formular seus conceitos sobre as coisas com suporte em suas internalizações individuais, cabendo ao professor a mediação desse processo, propiciando o trabalho com a linguagem geográfica e a apropriação de significados constituídos pelas problematizações, análises e negociações desenvolvidas com o aluno (CAVALCANTI, 2005).

Buscar refletir e analisar abordagens do pensamento geográfico permite a elaboração mais crítica de concepções pertinentes para nortear o trabalho do professor, pois, desde a compreensão das transformações da sociedade no espaço e da maneira como os alunos edificam o aprendizado, o educador se torna mais capacitado para proceder à mediação pedagógica, não apenas no campo da Geografia, mas também nas mais diversas áreas. Assim, exibir características e possibilidades do trabalho com a Geografia no ensino fundamental, problematizando os objetivos, o objeto de estudo e a formação dos conceitos e categorias, faz-se oportuno, na medida em que as informações podem ser disseminadas e (re) pensadas, fomentando um ensino-aprendizagem mais significativo e pertinente.

\section{Considerações finais}

Com o objetivo de debater acerca das interfaces das correntes do 
pensamento geográfico e a Geografia ensinada no Ensino Fundamental, enfatizando a "alfabetização geográfica" no século XXI, este ensaio realizou um estudo sobre as influências que o pendor Tradicional e a tendência Moderna exerceram no ensino formal da Geografia, bem como na maneira com que a aprendizagem se concebe na contemporaneidade, ressaltando os objetivos, objeto de estudo e a formulação dos conceitos geográficos pela criança.

Constatou-se que a propensão Tradicional, apoiada em conceitos naturais, notou a Geografia como Ciência descritiva de observação de elementos naturais que não se preocupou com as interações das pessoas com as questões sociais. Em oposição, a tendência Moderna centrou foco nas relações humanas imbricadas com a natureza em um contexto social dialético e dinâmico.

A Geografia Moderna, na perspectiva crítica, ao problematizar a realidade social no âmago das desigualdades e injustiças, amplia a capilaridade do trabalho com a Geografia na interação com outras ciências no âmbito econômico, político e sociocultural. Como Ciência humanizada, o viés político perpassa o aprendizado geográfico com vistas à transformação da ordem social. Concebida como prática social em relação à superfície terrestre, a Geografia ensinada afere significado ao responder problemas por meio da prática social.

Assentada na subjetividade dos sentimentos, na experiência, a Geografia ensinada privilegia o singular e a compreensão como base da inteligibilidade do mundo real, por intermédio de uma constante análise crítica, cada vez mais aprofundada, dos fatos e acontecimentos. O ensino da Geografia para as séries iniciais do ensino formal, nessa perspectiva, objetiva a aprendizagem de conceitos geográficos baseados no conhecimento de mundo, tornando-os significativos para o aluno, que os utiliza para atuação prática na vida social.

Ao contrário da visão positivista de ensino, fundamentada na transmissão mnemônica verticalizada do professor para o aluno, a proposta na contemporaneidade é utilizar múltiplas linguagens no ensino da Geografia e propiciar leituras díspares que possibilitam ampliar a compreensão crítica. Por intermédio da mediação semiótica 
para apreensão de signos e significados e a problematização de saberes diversos contextualizados com o entorno e vivências dos aprendizes, desenvolvem-se, paulatinamente, a criticidade e a autonomia dos alunos, promovendo a reflexão acerca de questões geográficas.

O ensino da Geografia como instrumento de compreensão da realidade, ao desenvolver conhecimento geográfico contextualizado, correlacionando sujeito, tempo e espaço em uma perspectiva hermenêutica de produção e transformação da sociedade, concorre para fomentar o cidadão, apto a intervir, responsavelmente, na sociedade.

O objetivo do Ensino Fundamental no século XXI, na perspectiva da Geografia, é "alfabetizar geograficamente" o aluno com amparo na apreensão de conceitos e categorias básicas que possibilitem a compreensão do espaço na interface com o sujeito histórico e suas múltiplas relações, ou seja, ampliar o olhar crítico sobre a realidade. Instigando a curiosidade do aluno, com problematizações e situações vivas de aprendizagem, possibilita-se compreender o mundo com a devida consciência geográfica, interpretando e utilizando os saberes na vida prática.

O ensino da Geografia, mais do que mero componente curricular, possibilita, por intermédio da alfabetização geográfica, o auxílio no desenvolvimento de habilidades para realização de observações, descrições, abstrações, problematizações e análises que facilitam a compreensão do mundo de maneira consciente. A maturidade para conquista da autonomia e de uma visão crítica global perpassa a capacidade de compreender o espaço geográfico nas suas interfaces com as relações sociais, culturais, políticas e econômicas. De tal modo, refletir acerca do ensino e aprendizagem no âmbito da Geografia sempre se fará oportuno, na medida em que propicia momentos de reflexão da práxis pedagógica. 


\section{Referências}

ALVES, Ana Paula Aparecida Ferreira.; SAHR, Cicilian Luiza Löwen Geografia ensinada - geografia vivida? Conceitos e abordagens para o ensino fundamental no Paraná. Revista Discente Expressão Geográficas, Florianópolis, ano 5, n. 5, p. 49-60, maio. 2009. Disponível em: <www. geograficas.cfh.ufsc.br>. Acesso em: 30 jun. 2013.

BRASIL, Ministério da Educação (MEC). Parâmetros Curriculares Nacionais: História (ensino fundamental). Brasília: MEC/SEF, 1997.

CALLAI, Helena. Copetti. Aprendendo a ler o mundo: a Geografia nos anos iniciais do ensino fundamental. Cadernos CEDES, Campinas, v. 25, n. 66, p. 227-247, mai./ago. 2005. Disponível em: <HTTP:/ / dx.doi.org/10.1590/S0101-32622005000200006>. Acesso em: 30 jun. 2013.

CASTELLAR, Sonia Maria Vanzella. Alfabetização em Geografia. Espaços da escola, Ijuí, v. 10, n. 37, p. 29-46, jul./set. 2000.

CASTELLAR, Sonia Maria Vanzella. (Orgs.). Educação geográfica, teorias e práticas docentes. São Paulo: Contexto, 2005.

CASTROGIOVANNI, Antonio Carlos. Apreensão e compreensão do espaço. In: CASTROGIOVANNI, Antonio Carlos. (Org.). Ensino de Geografia: práticas e textualização no cotidiano. Porto Alegre: Mediação, 2006. p. 9-81.

CAVALCANTI, Lana de Souza. Cotidiano, mediação pedagógica e formação de conceitos: uma contribuição de Vygotsky ao ensino de Geografia. Cadernos CEDES. Campinas. v. 25. n. 66, p. 185-207, mai./ago. 2005.Disponível em: <HTTP:/ / dx.doi.org/10.1590/S010132622005000200004>. Acesso em: 30 jun. 2013. 
CAVALCANTI, Agostinho Paula Brito; VIDIANA, Adler Guilherme. Fundamentos históricos da Geografia: contribuições do pensamento filosófico na Grécia antiga. In: GODOY, Paulo R. Teixeira de. (Org.). História do pensamento geográfico e epistemologia em Geografia. São Paulo: Cultura Acadêmica, 2010. p. 11-34. Disponível em: <http:/ / www.geoplan.net.br/material_didatico/livro $\%$ 20HISTORIA $\% 20$ DO $\%$ 20PENSAMENTO $\%$ 20GEOGR $\%$ C3\%81FICO $\% 20$ E $\% 20$ EPISTEMOLOGIA\%20EM\%20GEOGRAFIA\%5B1\%5D.pdf>. Acesso em: 30 jun. 2013.

CLAVAL, Paul. O território na transição da Pós-Modernidade. GEOgraphia. Niterói: UFF, ano 1, n. 2, p. 7-26, 1999.

CÔRREA, Roberto Lobato.et al. (Org.). Geografia: Conceitos e Temas. Rio de Janeiro: Editora Bertrand Brasil, 2003.

CORRÊA, Roberto Lobato. Região e organização espacial. 6. ed. São Paulo: Ática, 1998.

DELEUZE, Gilles; GUATTARI, Félix. O que é a Filosofia? São Paulo: Editora 34, 1992.

FREIRE, Pulo. Pedagogia da autonomia: saberes necessários à prática educativa. São Paulo: Paz e Terra, 1996.

FREITAS, Itamar. Fundamentos Teorico-Métodologicos para o Ensino de História (anos iniciais). São Cristovão: Editora UFS, 2010.

GADOTTI, Moacir. Pedagogia da práxis. São Paulo. Cortez, 2004.

GODOY, Paulo R. Teixeira de. Algumas considerações para uma revisão crítica da História do Pensamento Geográfico. In: GODOY, Paulo R. Teixeira de. (Org.). História do pensamento geográfico e epistemologia em Geografia. São Paulo: Editora UNESP; São Paulo: 
Cultura Acadêmica, 2010. p 145-156. Disponível em: <http:/ / www.geoplan. net.br/material_didatico/livro $\% 20 \mathrm{HISTORIA} \% 20$ DO $\%$ 20PENSAMENTO $\%$ 20GEOGR $\%$ C3\%81FICO $\% 20$ E $\% 20$ EPISTEMOLOGIA\%20EM\%20GEOGRAFIA\%5B1\%5D.pdf>. Acesso em: 30 jun. 2013.

HARTSHORNE, Richard. The nature of Geography. Lancaster: Association of American Geographers, 1939.

HARVEY, David. A condição pós-moderna. São Paulo: Edições Loyola, 1993.

ISNARD, Hildebert. O espaço geográfico. Coimbra: Almedina, 1982.

LACOSTE, Yves. A Geografia, isso serve em primeiro lugar para fazer guerra. Campinas: Ed. Papirus, 1988.

LEFÉBVRE, Henri. Espacio y política. Barcelona: Ediciones Penisula, 1976.

LIBÂNEO, José Carlos. Didática. São Paulo. Cortez, 1994.

MARQUES, Mário Osório. Conhecimento e modernidade em reconstrução. Ijuí: UNIJUÍ, 1993.

MASSEY, Doreen. Um sentido global do lugar. In: ARANTES, A. (Org.). O espaço da diferença. Campinas: Papirus, 2000. p. 176-185.

MORAES, Aantonio Carlos Robert. Geografia: pequena história crítica. 20. ed. São Paulo: Anablume, 1994.

MORIN, Edgar; EMILIO- ROGER Ciurana.; MOTTA Raúl Domingo. Educar na era Planetária. 2. ed. São Paulo: Cortez. Brasília-DF: UNESCO, 2007. 
NEVES, Joana. Entre o criticado e o legitimado: ANPUH, AGB e os Parâmetros Curriculares Nacionais. In: NEVES, Joana. Contra o consenso: LDB, DCN, PCN e reformas no ensino. João Pessoa: Sal da Terra, 2000. p. 07-27.

OLIVEIRA, Adriano Rodrigo. O uso de atlas municipais escolares e as formas de construção do conhecimento em sala de aula: analisando situações de ensino. Cadernos CEDES, Campinas, v. 23, n. 60, p. 218 230, ago. 2003. Disponível em: <http:/ / www.

scielo.br/pdf/ccedes/v23n60/17278.pdf>. Acesso em: 30 jun. 2013.

OLIVEIRA, Ariovaldo Umbelino de. (org.). Para onde vai o ensino de Geografia? 7. ed. São Paulo: Contexto, 1998.

PENTEADO, Heloísa Dupas. Metodologia do ensino de História e Geografia. 3. ed. São Paulo: Cortez, 2010.

PIAGET, Jean; INHELDER, Bärdel. A representação do espaço na criança. Porto Alegre: Artes Médicas, 1993.

RIBEIRO, Luiz Távora Furtado; MARQUES, Marcelo Santos. Ensino de História e Geografia. 2. ed. Fortaleza: Brasil Tropical, 2001.

ROCHA, José Carlos. Diálogo entre as categorias da Geografia: espaço, território e paisagem. Caminhos de Geografia, Uberlândia, v. 9, n. 27, p. 128-142, set. 2008.

SAHR, Wolf-Dietrich. Geografia crítica ou Geografia propositiva? Reflexões sobre conceitos e categorias geográficas na educação básica do Paraná. In: ENCONTRO SOBRE O SABER ESCOLAR E O CONHECIMENTO GEOGRÁFICO, 2., 2006, Ponta Grossa. Boletim de resumos. Ponta Grossa: UEPG, 2006. p. 27-34.

SANTOS, Milton. Por uma Geografia nova. São Paulo: HUCITEC, 1978. 
SANTOS, Milton. Técnica, espaço, tempo: globalização e meio técnicocientífico internacional. São Paulo: HUCITEC, 1994.

STRAFORINI, Rafael. Ensinar Geografia nas séries iniciais: o desafio da totalidade mundo. São Paulo: Anablume, 2004.

VESENTINI, José Willian. Geografia Crítica e Ensino. In: OLIVEIRA, A. W. (Org.). Para onde vai o Ensino de Geografia? 7. ed. São Paulo: Contexto. 1988. p. 30-38.

VESENTINI, José Willian. O novo papel da escola e do ensino da Geografia na época da Terceira Revolução Industrial. Terra Livre AGB, São Paulo, n. 11-12, p. 209-224, 1993.

VYGOTSKY, Lev Semenovich. A formação social da mente. São Paulo: Martins Fontes, 1999.

Recebido em 22/11/2013 Aprovado em 16/06/2014 